\title{
Optics in a changing education
}

\section{Manuel F. M. Costa}

Manuel F. M. Costa, "Optics in a changing education," Proc. SPIE 9664, Ninth International Topical Meeting on Education and Training in Optics and

Photonics, 966407 (24 October 2005); doi: 10.1117/12.2207561 and Photonics, 2005, Marseille, France 
Ref ETOP011

\title{
Optics in a Changing Education
}

\author{
Manuel F. M. Costa
}

Universidade do Minho, Departamento de Física

Tel. +351253 604334; Fax. +351253678981

e-mail: mfcosta@fisica.uminho.pt

4710-057 Braga - Portugal

\begin{abstract}
Education reforms are being implemented in many countries. The type and extent of the reforms vary significantly but share the increased significance given to Science Education that is becoming a major constituent of school curriculum. As well Technology Education is gaining more importance. Among the different fields of Science and Technology, Optics and Photonics have a major ever-increasing importance. In direct relation to development and economical growth questions, but also in our every day life. It is fundamental today to raise the importance of Optics in school syllabus and generalize it throughout all school levels..
\end{abstract}

\section{Keywords}

School' Education, scientific literacy, hands-on learning, science and society.

\section{Introduction}

\section{Summary}

Science and Technology have a major increasing role in today' society and in the lives of everyone of us(1). No further substantive and sustainable development of our economy and society may be foreseen without a leading enlarged and improved scientific and technological research. Improving science education is fundamental as well as effectively setting as major priority to raise the levels of scientific and technological literacy at all levels of our society. This applies to all fields of science and not only to applied science and technology. The fast developments on last decades render optics to a top level of importance. Importance to the development of many fields of technology and to the Society in general but to the development of a large range of other fields of Science.

In our days Optics and Photonics have a major increasing importance not only in Science and Technology but also in the widest range of aspects of our every day life. In the emerging Society of Information Light and Optics have a crucial importance, soon unsurpassable with the new developments in many photonics' fields including, fiber optics sensor and communications, image acquisition and processing, lasers, medical applications of light and lasers (photodynamic therapy, non-invasive medical diagnostics, surgery, tattoo removal and skin conditioning, tooth cleaning, ophthalmology,...), real time holography and data storage, optical computing, industrial non-destructive testing and metrology for quality control, environment monitoring (air and water quality, pollution detection, ozone layer depletion, ...) and life sciences, material processing (annealing, cutting, welding, drilling, ...), artwork cleaning and restoration,... 
It is of utmost importance that soon in their education the students get introduced or acquainted on those subjects of general optics -geometrical, physical and quantum- but also on more advanced subjects of striking importance: wave guidance, fiber optics and telecommunications, image digitalisation and processing, light-matter interaction, optical processing and computing,...

\section{New trends on science education}

Education reforms are being studied and implemented during the last years in many countries(2). The type and extent of the reforms vary significantly from country to country but they all share the increased significance given to Science Education that is becoming a major constituent of school curriculum. As well Technology Education is gaining more importance spite evident implementation difficulties.

Work related to Science teaching which constitutes a major part of the contents of Science education has also attracted educators and researchers extending also into more general aspects such as the teaching approaches adopted, the underlying learning theories, the teaching means and the use of new technologies (especially informatics), and also, other parameters that may affect the effectiveness of Science Teaching.

It urges the establishment of a science culture in our societies, as steady basis for the improvement of Science and its technological applications. In the Knowledge Society we try to implement, Optics and Photonics have a crucial importance not only in Science and Technology but also in the widest range of aspects of our every day life.

Experimental practical hands-on work is essential to the understanding of Science and thus fundamental to Science and Technology literacy. As an increasing number of decisions is dependent upon Science and Technology developments, in order for the citizen of a democratic society to be able to participate he should be S\&T literate but also must have cognitive skills permitting decisions on incomplete knowledge and science education do provide a natural framework towards the development of such skills.

A sound Science Education beginning as earlier as at pre-school level is fundamental to a good development of fundamental skills the new generations will definitely need in order to cope with the requirements of a new Knowledge based economy and Society.

Efforts towards the improvement of Science' education should be generalized all over Europe aiming the sound establishment of a Science culture in our societies and to guarantee a steady basis for the improvement of Science and its technological applications. It urges to improve the quality and effectiveness of in-school Science learning. To do so one of the best paths is by leading school students to an active volunteer and committed participation in the teaching/learning process through hands-on practice and experimentation, making intensive use of the new instruments and resources of the Information Society.

\section{Disseminating optics in-school education}

It is fundamental today to raise the importance of Optics in school syllabus and generalize it throughout all school levels. Positive steps are being given in different 
countries. The Hands-on Optics project in the USA and the Optica'XXI projects within the "Hands-on Science"(3) EU' network (www.hsci.info) are examples of good practice that should be developed and replicated extensively.

Light and optics are subjects that directly relates to one of our major senses. This makes this topic attractive and easily accessible to most of the students, from early ages. It is of utmost importance that soon in their education the students get introduced or acquainted on those subjects of general optics - geometrical, physical and quantum- but also on more advanced subjects of striking importance - wave guidance, fiber optics and telecommunications, image digitalization and processing, lasers, optical processing and computing,... It has been proved that the subjects as the nature of light and colour can be introduced as early as in pre-schools. The basics of some subjects are easily understood even by 5 years old children: addition of colours (often older students take longer to understand the process because they are used to the subtractive ink's colour mixing), reflection of light and internal total reflection (a piece of sweet flavoured jelly may act as an wonderful... light guide!), refractive bending of light...(4).

The new stringent requirements of the modern society demand not only the gathering of specific knowledge but also and specially of the competencies the ability of acting interactively to be able to find, analyze and solve new interdisciplinary problems. The best way of achieving an adequate formation of our students on these issues is by inducing the students to an active committed participation in the teaching/learning process, through practice and experimentation. Making use of the new instruments and resources of the Information Society.

The pedagogic approach we suggest to be used relies on a functional integration of different pedagogical theories and practices namely the constructivism, conceptual learning and pro-active learning by hands on experimentation and research. Responsibility, critical reasoning and observation, method and flexibility, interdisciplinarity, volunteer self-rewarding commitment, joint efforts and teamwork, are the main keywords that should guide all pedagogical activities.

Specifically our pedagogic approach to the problem relies essentially on three vectors: hands on experiments (learning and self learning by experiment practices - the scientific method); conceptual learning (learning and understanding fundamental concepts in optics and science in general by the integration of qualitative and intuitive understanding with quantitative methods, in order to promote inventive behaviour and problem solving skills); and, intensive use of ICT (computer simulations and demonstrations, interactive multimedia material, automated virtual laboratories, web-based networks for exchange of ideas and experience and pedagogic tools and materials, in a national and international basis).

\section{Conclusion}

The development of optics and photonics requires a large number of well prepared highly motivated scientist and technicians that should be teach and trained as early and as efficiently as possible in a positive rewarding environment. Furthermore not only the importance of Optics, as a major field of Science, should be positively recognized by the Society, but also a good scientific literacy should be established. 


\section{Acknowledgement}

The author wish to express his acknowledgment to the European Commission for the support to the "Hands-on Science" Comenius 3 network (n. 110157-CP-1-2003-1-PTCOMENIUS-C).

\section{References}

1. P. G. Michaelides; "State of the Art of Science Teaching", proceedings of the 1st International Conference on Hands on Science, Teaching and Learning Science in the XXI Century" em Ljubljana, Slovenia, Juçy 2004, pp. 9-14 (2004).

2. Manuel F. M. Costa; "Science in a changing Education: The contribution of the Handson Science network to the improvement of science education", proceedings of the "2nd International Conference on Hands-on Science: Science in a changing Education", Rethymno, Grécia, July 2005, pp. 25-26 (2005).

3. www.hsci.info, www.hsci-pt.com.

4. Manuel F. M. Costa, "Learning optics at basic schools by experimentation", proceedings of the 1st International Conference on Hands on Science, Teaching and Learning Science in the XXI Century" em Ljubljana, Slovenia, July 2004, pp. 19-22 (2004). 